\section{The Dissimilarity between Patients' and Relatives' Perception of Eating Disorders and Its Relation to Patient Adjustment}

\author{
YOLANDA QUILES MARCOS \\ Miguel Hernández University, Spain \\ JOHN WEINMAN \\ King's College. University of London, UK \\ $M^{\text {a }}$ CARMEN TEROL CANTERO \\ Miguel Hernández University, Spain \\ MARINA BELÉNDEZ VÁZQUEZ \\ University of Alicante, Spain
}

\section{JHP}

Journal of Health Psychology Copyright () 2009 SAGE Publications Los Angeles, London, New Delhi, Singapore and Washington DC www.sagepublications.com Vol 14(2) 306-312 DOI: $10.1177 / 1359105308100215$

\section{Abstract}

This study aims to examine the relation between the degree of dissimilarity in patients' and relatives' perception of eating disorders (ED) and patient adjustment. Sixty ED patients and their relatives were interviewed. They completed the Spanish version for ED of the Revised Illness Perception Questionnaire (IPQ-R). Patients who agreed with their relatives that their illness was highly distressful, a chronic condition and with high identity, showed higher psychological distress than patients who did not agree with their relatives. When patients and relatives had fairly positive perceptions of illness controllability and curability, these patients showed lower levels of depression and anxiety.
ACKNOWLEDGEMENTS. The authors would like to thank the following individuals for their expertise and help in completing this manuscript: Kevin Dodd, PhD, Helen Meissner, PhD, Lila Finney Rutten, PhD and Janice Solomon, all of whom work at the National Cancer Institute.

COMPETING INTERESTS: None declared.

ADDRESS. Correspondence should be directed to: YOLANDA QUILES MARCOS, Departamento Psicología de la Salud, Universidad Miguel Hernández de Elche, Avda. de la Universidad s/n C.P. 03202, Elche (Alicante), Spain. [Tel. +34 966658314; email: y.quiles@umh.es]

\section{Keywords}

- adjustment

- eating disorders

- illness perception

- relatives'perception

- revised illness perception questionnaire 


\section{Introduction}

HOW INDIVIDUALS perceive a given illness has been associated with a variety of important behaviours and emotional responses in patients, careers and professionals (Figueiras \& Weinman, 2003; Hagger \& Orbell, 2003). One theoretical model that has addressed how cognitive factors influence coping behaviours and outcomes is the Self-Regulation Model (SRM; Leventhal, Meyer, \& Nerenz, 1980). In the SRM model, illness perception is organized around five common dimensions: cause; consequences; identity; timeline; and control/cure. The cause dimension represents the beliefs regarding the factors that are responsible for causing the illness or disease. The consequences of the illness refer to beliefs regarding the impact of the illness on overall quality of life or how it may affect functional capacity. Illness identity refers to statements regarding beliefs about the illness label and knowledge about its symptoms. Timeline refers to the individual's beliefs about the course of the illness. And the control/cure dimension refers to the sensation of empowerment regarding performance of coping behaviours or the efficacy of treatment.

Within the literature about eating disorders (ED), little has been written about the influence of patients' perceptions of their illness on their adjustment. Recently, three studies examined illness perception in ED patients. Holliday, Wall, Treasure and Weinman (2005) compared patients' results with those of a normal control sample, and found that anorexia nervosa patients viewed their illness as chronic and highly distressful, with strong negative consequences and negative perceptions of illness controllability and curability, which contrasted with the more optimistic beliefs held by lay participants. Quiles, Terol, Romero and Pagán (2007) showed that patients' illness perceptions were related to illness adaptation. Illness identity was associated with emotional and psychosocial adjustment and having faith that treatment may control the illness was related to positive benefits for ED patients. Finally, a recent study conducted by Stockford, Turner and Cooper (2007) suggests significant relationships between illness perception and stage of change.

Recent qualitative research and clinical work in ED suggests that appraisals about the illness itself can also play an important role in determining carers' behavioural and affective responses to the illness (Treasure, Gavan, Todd, \& Schmidt, 2003; Whitney, Haigh, Weinman, \& Treasure, 2007). In the case of chronic illness, it may be assumed that the beliefs held by people within a patient's social network (expressed in the form of advice or opinions) can affect the patient's illness representation and healthrelated behaviour (Figueiras \& Weinman, 2003; Heijmans, de Ridder, \& Bensing, 1999; Salewski, 2003). Heijmans et al.'s (1999) research with Addison's Disease and Chronic Fatigue Syndrome patients demonstrated the importance of the role of significant others and their belief in patients' coping with and adapting to chronic illness. More recently, the illness perception approach proposed by Leventhal for myocardial infarction (MI) patients suggests that the degree of match/mismatch between the patient's and partner's perception of the MI could be associated with a range of recovery outcomes (Figueiras \& Weinman, 2003).

The aim of the present study was to explore the extent to which the perceptions of ED in patients and their relatives were similar and whether the degree of congruence in illness perception might be related to patients adjustment. To be more specific, it was hypothesized that high dissimilarity scores in illness perception dimensions between patients and relatives could be associated with maladaptive adjustment as shown by Figueiras and Weinman (2003) and Heijmans et al. (1999).

\section{Method}

\section{Participants}

A total of 98 female ED outpatients (response rate $=98 \%$ ) attending the Unit for Eating Disorders at the University Hospital of San Juan in Spain, and their relatives $(N=60)$, were recruited (38 relatives were not available). The main reason for the nonparticipation of relatives was that the vast majority of older patients came to the unit alone. There were no differences in baseline variables between patients whose relatives were interviewed and those whose relatives were not available. Data collection took place in the unit for eating disorders, all participating patients and their relatives gave written informed consent. Patients had a primary DSM-IV diagnosis of anorexia nervosa (restrictive type $=43$; purging type $=17$ ), bulimia nervosa (purging type $=$ 24 ; non-purging type $=3$ ) or unspecified eating disorders $(n=11)$. The self-reported mean length of illness was 3.8 years $(\mathrm{SD}=3.8)$. The majority of the relatives were females $(80.6 \%), 75$ per cent were patients' mothers, 15 per cent their fathers, 5 per cent 
their partners and 5 per cent their sisters. The mean age for patients was 20.8 ( $\mathrm{SD}=5.61$; range $=$ $12-34$ ), and for relatives, it was 45 ( $\mathrm{SD}=8.64$, range $=19-60$ ).

\section{Measures}

Illness perception Patients' perceptions of eating disorders were assessed using the Spanish version for ED (Quiles, Terol, Tirado, \& Beléndez, 2007) of the Revised Illness Perception Questionnaire (IPQ-R; Moss-Morris et al., 2002). This questionnaire measures participants' illness beliefs over eight dimensions: identity; timeline; consequences; cause; cyclical time-line; personal control; treatment control; and emotional representation. However, and as in previous research (Figueiras \& Weinman, 2003; Heijmans et al., 1999), only the cause dimension was considered in descriptive analyses.

This scale has also been used for other psychological disorders, such as, depression and schizophrenia (Brown et al., 2001; Lobban, Barrowclough, \& Steven, 2005). A slightly re-worded version was used for the relatives' perception of the patients' ED.

Psychosocial adjustment The PAIS (Psycho social Adjustment to Illness Scale; Derogatis \& Lopez, 1983) was used to assess adjustment to illness. This scale has also been used for other mental illnesses, such as, generalized anxiety disorder patients (Lieh et al., 2004). The questionnaire covers seven dimensions including Health Care Orientation, Vocational/Educational Rehabilitation, Domestic Environment, Sexual Relationships (this subscale was only used with patients over 16), Social Environment and Psychological Distress. The scale is designed to provide information on global adjustment as well as adjustment in specific areas. This instrument was used with the patient group only.

Anxiety and depression The HADS (Hospital Anxiety and Depression Scale; Zigmond \& Snaith, 1983) is a 14-item scale that assesses anxiety and depression. This questionnaire was translated into Spanish, and showed acceptable psychometric properties (López-Roig et al., 2000). This instrument was used with the patient group only.

\section{Analysis}

Illness perception Independent sample $t$-tests were computed to assess the differences in illness perception scores between ED patients and relatives.
Degree of similarity between patients' and relatives' illness perceptions

In order to assess the degree of similarity in patient and relative illness perceptions, we decided to develop a comparative patient-relative score (the same as Figueiras \& Weinman, 2003), which attempted to take into account not only the degree of similarity of their perceptions, but also the relative level of the score (i.e. high/low) for each illness perception component. This analysis was only carried out with the 60 patients whose relatives also participated. We used a simple classification system based on the mid-point for each component. Thus, patient and relative scores for each of the seven components of ED representation were recoded according to the mid-point for each dimension. We classified patients' and relatives' scores as: (a) scores for patients and relatives below the mid-point and; (b) scores for patients and relatives above the mid-point. This gives rise to three broad groupings: (1) similar high scores are found in couples where both the patient's and relative's score is above the mid-point; (2) similar low scores are found where both score below the mid-point; (3) conflicting perceptions are, therefore, those where patients and relatives have different scores (i.e. patient score is below; relative score is above, or vice-versa). Since there were relatively small numbers in the second group, we could only compare similar high scores and conflicting perceptions.

\section{Similar illness perception and outcome}

To determine whether the degree of similarity of patient-relative illness perception was associated with adjustment, the two groups (similar high scores and conflicting perception) were compared for each adjustment measure using the Student $T$-test for independent samples. This analysis was only carried out with the 60 patients whose relatives also participated. Given the large differences in the sample sizes of the groups, authors made corrections for the homogeneity of variances.

\section{Results}

There were no significant differences between illness perception for patients whose relatives were interviewed $(N=60)$ and those whose relatives were not available $(N=38)$. In general, ED patients and their relatives had high scores in consequences, timeline, personal control, treatment control and emotional representation. In contrast, they scored 
QUILES MARCOS ET AL.: THE DISSIMILARITY BETWEEN PATIENTS' AND RELATIVES'

Table 1. Similar High Scores and Dissimilarity Scores in Illness Perception and Psychosocial Adjustment

\begin{tabular}{|c|c|c|c|c|c|c|c|}
\hline DIMENSSION & $\begin{array}{l}N \\
\text { Group A }\end{array}$ & $\begin{array}{l}N \\
\text { Group B }\end{array}$ & $\begin{array}{l}\text { PSYCHOSOCIAL } \\
\text { ADJUSTMENT }\end{array}$ & $\begin{array}{l}\text { MEAN } \\
\text { Group A }\end{array}$ & $\begin{array}{l}\text { MEAN } \\
\text { Group B }\end{array}$ & $T$ & $d$ \\
\hline PERSONAL & 38 & 22 & ANXIETY & 7.50 & 13.09 & $-4.01 * * *$ & 1.10 \\
\hline CONTROL & & & DEPRESSION & 4.52 & 7.04 & $-2.17 *$ & 0.58 \\
\hline EMOTIONAL & 18 & 42 & DISTRESS & 13.88 & 10.85 & $2.08 *$ & 0.54 \\
\hline REPRESENTATION & & & GLOBAL & 50.11 & 38.59 & $2.25 *$ & 0.58 \\
\hline $\begin{array}{l}\text { TREATMENT } \\
\text { CONROL }\end{array}$ & 22 & 38 & ANXIETY & 7.40 & 10.48 & $-2.25^{*}$ & 0.60 \\
\hline \multirow[t]{2}{*}{ CONSEQUENCES } & 25 & 35 & VOCATIONAL & 4.76 & 2.94 & $2.07 *$ & 0.56 \\
\hline & & & SEXUAL & 6.84 & 4.20 & $2.17 *$ & 0.58 \\
\hline \multirow[t]{2}{*}{ TIMELINE } & 15 & 45 & DISTRESS & 14.60 & 10.82 & $2.85^{* *}$ & 0.82 \\
\hline & & & DOMESTIC & 8.46 & 4.86 & $2.69 * *$ & 0.78 \\
\hline CYCLICAL TIMELINE & 7 & 53 & ANXIETY & 14.57 & 8.88 & $2.55 *$ & 0.99 \\
\hline IDENTITY & 10 & 50 & DISTRESS & 13.40 & 11.61 & $2.11 *$ & 1.00 \\
\hline
\end{tabular}

$* \mathrm{p}<0.05: * * \mathrm{p}<0.01: * * * \mathrm{p}<0.001 \mathrm{~d}$ : effect size

A: Group Patient and Relative with similar high scores

B: Group Patient and Relative with dissimilarity scores

moderately in illness identity and cyclical timeline. Patients and relatives showed higher scores in 'psychological cause' (e.g. own behaviour, emotional state, personality and mental attitude) and in 'specified ED cause' (e.g. media influence, need to be perfect, peer pressure), otherwise the lowest scores were in 'external cause' (e.g. chance or bad luck, poor medical care in past, pollution and germen or virus) and in 'risk cause' (e.g. altered immunity, overwork, hereditary, accident, smoke and alcohol).

Paired $t$-tests revealed no significant differences between the mean scores for ED patients and their relatives in identity, control, cure, cyclical timeline and emotional representation dimensions. However, there were differences between ED patients and their relatives regarding the time-line $(t=-4.8 p<.001)$ and consequence $(t=-2.41 p<.01)$ dimensions. Relatives had more pessimistic ideas about the evolution and the consequences of the illness than patients. Relatives and patients differed significantly in the causal dimension. Relatives identified risk cause $(t=-4.06 p<.001)$ and specified ED cause $(t=-3.72$ $p<.001)$ more frequently than patients.

Table 1 presents only the significant results for psychosocial adjustment, once the patients from the two groups (similar high scores/conflicting scores in each illness perception dimension) were compared. In Personal Control dimension, patients from relatives with similar high $(N=38)$ scores showed lower HADS depression and HADS anxiety than the other group $(N=22)$. And in Timeline dimension, patients from relatives with similar high scores
$(N=15)$ showed lower PAIS domestic environment adaptation and PAIS higher psychological distress than the other group $(N=45)$.

\section{Discussion}

These results show that eating disorder patients and their relatives have broadly similar beliefs about the illness. The most positively similar perceptions of eating disorders between patients and relatives were found for the personal and treatment control dimensions. Both relatives and ED patients believed that they could control the illness either by treatment or by their own behaviour. On the other hand, the most negatively similar perceptions were found for the consequence, timeline and emotional representation dimensions. They were pessimistic about the future evolution of the illness and the impact of the illness on the overall quality of life. However, patients and their relatives differ in their beliefs about the consequences and the evolution of the illness. ED patients were more optimistic than their relatives about the evolution of their illness and rated the consequences less seriously. This could be related to the ambivalence that these patient often experience about change. In the same way, these discrepancies between patient and carer perceptions could contribute to expressed emotion. Expressed emotion and ambivalence are two of the major difficulties in treating women with ED (Barrowclough \& Holey, 2003; Blake, Turnbull, \& Treasure, 1997; Kyriacou, Treasure, \& Schmidt, 2008; Winn et al., 2007). 
JOURNAL OF HEALTH PSYCHOLOGY 14(2)

In the current study, an attempt is made to explore the relation between similar or dissimilar illness representations in patients and their relatives and patients' adjustment. We compared the psychosocial adjustment of patients whose relatives had similar high scores for each dimension of illness perception to that of patients with perceptions that conflicted with those of their relatives. The results show that although patients and relatives agree in their perception of the illness, this is not enough to achieve better adjustment, since agreement must be positive. In the case of ED, patients and relatives must share an illness perception characterized by high personal/treatment control and low identity, timeline, cyclical timeline and emotional representation. When patients and relatives had similar positive perceptions of illness, with high scores in treatment control and personal control dimensions, these patients had better adjustment than the patients whose perceptions conflicted with those of their relatives. Whereas similar negative perception of ED, characterized by high scores in identity, consequences, timeline, cyclical timeline and emotional representation dimensions, were associated with poorer patient adjustment. Our findings are similar to those of Figueiras and Weinman (2003).

An important question that arises from these results is the value of examining to what extent conflicting patient-relative perception can influence patients' well-being. If dissimilar patient-relative perception involves poorer adjustment than when perceptions are similar, then conflicting perceptions could provoke a tense situation, and consequently patients' well-being is worse. For example, if a relative believes that a patient has control over his/her illness, but the patient has fairly negative perceptions of illness controllability, relations between them would be very strained. In this situation, it is possible that relatives might make comments to patients such as: 'if you really wanted to, you could get over your illness', or 'if you were more compliant with medical regimes, you would get better'. These comments could foster self-blame, anxiety, worse adaptation and relationships would become more conflictive. On the other hand, Figueiras and Weinman (2003) suggested that conflicting views could also be associated with positive health outcomes. Thus, what may be important is that at least one member, patient or relative, has a positive perception of the illness and could encourage or motivate the other member. In this respect, it would be interesting to identify the factors that are connected with similar positive perceptions about the illness in patients and relatives. Furthermore, it would be necessary to investigate whether it makes a difference as to which person (patient or relative) has the positive (or negative) view of health outcomes. In this study, however, there were not enough members to examine these two groups separately. It would have also been interesting to investigate the differences according to whether the patients in the conflicting groups were in the high or low category. Nevertheless, future studies should explore alternative explanations; maybe it does not matter if the carer's view is similar or dissimilar to the patient's view-but maybe if the patient's view is negative - their adjustment is negative. It would have also been interesting to examine the relative's own well-being/psychological distress as a result of their perceptions and the similarity/dissimilarity of their beliefs to that of the patient.

Finally, some methodological limitations of the present study need to be noted. First, the representativeness of the sample consisted of approximately 60 per cent of anorexic patients and no separate analyses were carried out for different diagnostic groups. However, the proportion of anorexics and bulimics was similar to that found in other units for the treatment of eating disorders. A second limitation is related to the small sample of relatives. Third, since there were a small number of patients and relatives who had similar low scores in each dimension of illness representation, we were not able to compare this group to those patients and relatives who had similar high scores. With respect to the instrument, it is important to point out the limitations of the Spanish version of the IPQ for patients and relatives. To be exact, the translation of the measure from English to Spanish and adapting it for carers may have had an impact on the psychometric properties of the measure. The method for grouping patients and relatives per degree of congruence for each of their illness perception component scores was based on the range's mid-point for each component. This inevitably results in loss of variance in the data, and is obviously a fairly conservative way of creating groups. Future studies should explore alternative methods for these 


\section{QUILES MARCOS ET AL.: THE DISSIMILARITY BETWEEN PATIENTS' AND RELATIVES'}

purposes. Finally, the study has a cross-sectional design and does not allow any causal inferences to be drawn from the findings.

\section{References}

Barrowclough, C., \& Hooley, J. M. (2003). Attributions and expressed emotion: A review. Clinical Psychology Review, 23(6), 849-880.

Blake, W., Turnbull, S., \& Treasure, J. (1997). Stages and processes of change in eating disorders: Implications for therapy. Clinical Psychology and Psychotherapy, 4(3), 186-191.

Brown, C., Dunbar-Jacob, J., Palenchar, D. R., Kelleher, K. J., Bruehlman, R. D., Sereika, S., \& Thase, M. E. (2001). Primary care patients' personals illness models for depression: A preliminary investigation. Family Practice, 18(3), 314-320.

Derogatis, L. R., \& Lopez, M. C. (1983). PAISSR—administration, scoring and procedural manual. Baltimore, MD: Clinical Psychometric Research.

Figueiras, M. J., \& Weinman, J. (2003). Do similar patient and spouse perceptions of myocardial infarction predict recovery? Psychology and Health, 18(2), 201-216.

Hagger, M. S., \& Orbell, S. (2003). A meta-analytic review of the common-sense model of illness representations. Psychology and Health, 18(2), 141-184.

Heijmans, M., de Ridder, D., \& Bensing, J. (1999). Dissimilarity in patients' and spouses' representations of chronic illness: Exploration of relations to patient adaptation. Psychology and Health, 14(3), 451-466.

Holliday, J., Wall, E., Treasure, J., \& Weinman, J. (2005). Perceptions of illness in individuals with anorexia nervosa: A comparison with lay men and women. International Journal of Eating Disorders, 37(1), $50-56$.

Kyriacou, O., Treasure, J., \& Schmidt, U. (2008). Expressed emotion in eating disorders assessed via selfreport: An examination of factors associated with expressed emotion in careers of people with anorexia nervosa in comparison to control families. International Journal of Eating Disorders, 41(1), 37-46.

Leventhal, H., Meyer, D., \& Nerenz, D. (1980). The common sense representations of illness danger. In $\mathrm{S}$. Rachman (Ed.), Contributions to medical psychology (vol. 2, pp. 7-30). Oxford: Pergamon Press.

Lieh, T., Liang, C., Kuang, Y., Dar Lee, Y., Cheng, C., \& See, P. (2004). The adjustment to illness in patients with generalized anxiety disorder is poorer than that in patients with end-stage renal disease. Journal of Psychosomatic Research, 57(2), 165-170.
Lobban, F., Barrowclough, C., \& Steven, J. (2005). Assessing cognitive representations of mental health problems: The illness perception questionnaire for schizophrenia. British Journal of Clinical Psychology, 44(2), 147-162.

López-Roig, S., Terol, M. C., Pastor, M. A., Massutí, B., Rodríguez-Marín, Neipp, J. et al. (2000). Ansiedad y Depresión: Validación de la Escala HAD en Pacientes Oncológicos. Revista de Psicología de la Salud, 12(3), 127-155.

Moss-Morris, R., Weinman, J., Petrie, K. J., Horne, R., Cameron, L. D., \& Buick, D. (2002). The Revised Illness Perception Questionnaire (IPQ-R). Psychology and Health, 17(1), 1-16.

Quiles, Y., Terol, M. C., Romero, C., \& Pagán, G. (2007). Illness perception in eating disorders and psychosocial adaptation. European Eating Disorders Review, 15(5), 373-384.

Quiles, Y., Terol, M. C., Tirado, S., \& Beléndez, M. (2007). Estructura factorial de la versión española del cuestionario de percepción de la enfermedad revisado (IPQ-R) en pacientes con un trastorno del comportamiento alimentario y sus familiares. Cuadernos de Medicina Psicosomática y Psiquiatría de Enlace, 83, 9-22.

Salewski, C. (2003). Illness representations in families with a chronically ill adolescent: Differences between family members and impact on patients' outcome variables. Journal of Health Psychology, 8(5), 587-598.

Stockford, K., Turner, H., \& Cooper, M. (2007). Illness perception and its relationship to readiness to change in the eating disorders: A preliminary investigation. British Journal of Clinical Psychology, 46(2), 139-154.

Treasure, J., Gavan, K., Todd, G., \& Schmidt, U. (2003). Changing the environment in eating disorders: Working with carers/families to improve motivation and facilitate change. European Eating Disorders Review, 11(1), 25-37.

Whitney, J., Haigh, R., Weinman, J., \& Treasure, J. (2007). Caring for people with eating disorders: Factors associated with psychological distress and negative caregiving appraisals in carers of people with eating disorders. British Journal of Clinical Psychology, 46(Pt 4), 413-428.

Winn, S., Perkins, S., Walwyn, R., Schmidt, U., Eisler, I., Treasure, J. et al. (2007). Predictors of mental health problems and negative caregiving experiences in careers of adolescents with bulimia nervosa. International Journal of Eating Disorders, 40(2), 171-178.

Zigmond, A. S., \& Snaith, R. D. (1983). The hospital anxiety and depression scale. Acta Psychiatrica Scandinavica, 67, 
JOURNAL OF HEALTH PSYCHOLOGY 14(2)

\section{Author biographies}

YOLANDA QUILES MARCOS is a lecturer for the Health Psychology Department at the University Miguel Hernández of Spain. She teaches Health Psychology and Social Psychology. Her main research interests are illness perception, coping and eating disorders.

JOHN WEINMAN is professor of Psychology as applied to Medicine at the Institute of Psychiatry in the King's College London. He is a Fellow of the British Psychological Society and of the Academy of Behavioral Medicine Research. His main research areas are cognition and health and selfregulation and self-management in chronic illness.
$M^{a}$ CARMEN TEROL is a lecturer for the Health Psychology Department at the University Miguel Hernández of Spain. She teaches Health Psychology and Social Psychology. Her main research interests are coping and social comparison in chronic illness.

MARINA BELÉNDEZ is a lecturer for the Social Psychology Department at the University of Alicante of Spain. She teaches Social Psychology. Her main research interests are illness perception and self-regulation in chronic illness. 